\title{
Plot inflation in Greater Weatherfield: Coronation Street in the 1990s
}

Book or Report Section

Accepted Version

Smart, B. (2014) Plot inflation in Greater Weatherfield:

Coronation Street in the 1990s. In: Bignell, J. and Lacey, S. (eds.) British Television Drama: Past, Present and Future, 2nd edition. Palgrave Macmillan, Houndsmills, Basingstoke, pp. 7083. ISBN 9781137327567 Available at https://centaur.reading.ac.uk/71885/

It is advisable to refer to the publisher's version if you intend to cite from the work. See Guidance on citing.

Publisher: Palgrave Macmillan

All outputs in CentAUR are protected by Intellectual Property Rights law, including copyright law. Copyright and IPR is retained by the creators or other copyright holders. Terms and conditions for use of this material are defined in the End User Agreement.

\section{www.reading.ac.uk/centaur}

\section{CentAUR}

Central Archive at the University of Reading 
Reading's research outputs online 


\section{Plot inflation in Greater Weatherfield:}

\section{Coronation Street in the 1990s}

In a recent overview of developments in soap opera scholarship Christine Geraghty suggests that critical orthodoxy has arisen, stifling further analysis of the form. ${ }^{i}$ Current work concentrates upon the presupposed fixed conventions of soap opera as a form, neglecting to identify and consider changes that appear within the programmes, which might potentially contradict previous generalized definitions of soap opera as a genre. In particular, Geraghty identifies the absence of detailed textual analysis of British soaps:

Textual readings of soaps need to become more nuanced and to be unhooked from questions of representation. The 1980s practice of reading for ideological positions and contradictions needs to be reinforced with (or undermined by) an account of their visual and aural textual features (including performance) and an assessment of how such features work with or against the grain of the particular stories being told. Textual analysis of this kind would need to be taken across episodes to look at the rhythms, repetitions and changes in style and would need to incorporate an account of the way in which these elements have changed over time.ii 
This chapter is written in response to this call for new works of textual analysis of British soap opera. In my analysis of Coronation Street (ITV, Granada, 1960-) during the 1990s, I identify specific instances when textual change resulted from profound transformations to the show's production technologies and broadcasting conditions, examining how these changes to visual and narrative organization altered the programme's overall.

\section{Snooping on Don Brennan from the Back Garden: Watching Coronation Street in the 1990s.}

Long before my eventual career as Television Studies academic, I overheard (and occasionally contributed to) many conversations about soap operas in library staff rooms. These generally took two forms: judgement over the rightness or wrongness of characters and their actions ("I was really sorry for Gail when Martin had a one night stand with that nurse"), and speculation as to how events would progress ("Who do you think shot Grant Mitchell?"). More general consideration of soaps as programmes in themselves was infrequent, generally voiced as complaints about how they weren't what they used to be ("It's too depressing these days/ there are too many young people/ gangsters in it now").

Because of this, one atypical discussion has always stayed in my mind. This conversation was unusual because we weren't talking about Rita's marriage to Ted Sullivan or Emily Bishop's protracted 
nervous breakdown in the episode (\#3393, 5 June 1992), but how the programme was shot and the means by which the director had conveyed information to the audience. A routine living room scene ("Don Brennan calls on Julie again who tells him that she's seeing other men") had been shown, not from where it took place, but partially observed though a window from Julie's back garden. What was all that about? We couldn't understand what it was supposed to signify. Did this mean that somebody else, aware on Don's actions, was spying on him? Surely not Ivy? If so, then why weren't we subsequently shown who the watcher in the garden was?

What we didn't understand at the time was that the scene hadn't been realised in this odd way because of anything to do with Don's hoped-for infidelity, but because the visual grammar of Coronation Street was changing before our eyes. Although much of Coronation Street's appeal, and the emotional investment that dedicated viewers' place in it, derive from a sense of familiarity and continuity, throughout the 1990s the form, structure and feel of the programme was radically, but largely invisibly, changing. What was significant about the audience being placed in Julie Dewhurst's garden was that momentarily - through an incidence of badly misjudged direction - the curtain lifted and viewers such as my colleagues and myself were made aware of the changing ontology of Coronation Street as it occurred. 


\section{Changing production and broadcast of Coronation Street in the}

1990s.

Coronation Street underwent two near-concurrent major changes to its production practice in the late 1980 s, inexorably altering both the form and dramatic function of the programme. The first change was switching the recording of location sequences from $16 \mathrm{~mm}$ film to videotaped Outside Broadcast (OB) in 1988. iii More transportable and flexible OB recording technology enabled the use of many more exterior scenes than previously, creating a more mobile mise-en-scene closer to the contemporary continuing series Brookside (Channel 4, Mersey TV, 1982-2003) and The Bill (ITV, Thames, 1984-2010). This increase in location sequences meant that for the first time Coronation Street could regularly, rather than infrequently, go beyond the familiar cobbled street and into the places and institutions of the wider world (hereon referred to as 'Greater Weatherfield'), featuring three or four outside locations each week by the 1990 s. ${ }^{\text {iv }}$

The second major change was a move to three episodes per week in October 1989, having previously run twice weekly since its launch in 1960. Transmitting an extra edition of its highest-rated programme was a highly popular move within the ITV network, which had long suffered a problem attracting substantial audiences on Friday nights.v Coronation Street's executive producer David Liddiment (1988-92), explained the move to a third episode: 
We had already made the decision to increase the volume of location material and we were looking at a schedule to give us more time on location and the same time in the studio. I didn't want the process we'd started, of increasing the production values of an episode, to be neutralised by the need to make a third episode. I wanted to make sure we could continue to enhance the production values of the programme and do a third episode.vi

Interestingly, Liddiment's justification links both changes (mode of recording and amount of episodes) together, with increased location scenes constituting an increase in "production values", an artistic advance that must be safeguarded.

To prepare for the introduction of the third episode, extensive changes were made to several essential aspects of the programme. The composition of the street itself was altered, with the Community Centre and Baldwin's Casuals clothing factory demolished, creating space for three new homes. New houses required new residents, broadening the social mix of the series' characters, a change that creating fresh dramatic possibilities for the series, according to producer Mervyn Watson (1982-85, 1989-92):

The reconstruction of the even-numbers side of the street has opened up a new swathe of stories and characters. It was appropriate that the first occupants of No 6 Coronation Street 
should be newcomers, the hot-tempered newlyweds Des and Steph Barnes. By mixing old and new, our well-established characters have been given new possibilities and a new lease of life.vii

To fill the 52 extra episodes per year the number of regular and semiregular characters increased from around 30 to around 40 . To incorporate the greater number of characters and locations, the show became faster-paced, with more (shorter) scenes per episode.

At the same time that the new OB technology was introduced, radical alterations were made to Granada's facilities for the interior studio scenes, with the vast Stage One studio, used exclusively for Coronation Street production, opening in 1990vii. Permanent standing sets could now be kept for interiors of all the Street's houses and businesses for the first time, previously only kept for the main Rover's Return interior. ${ }^{\text {ix }}$ Further changes came with the introduction of Avid digital editing technology, greatly increasing opportunities for postproduction. $\mathrm{x}$

Like Watson, Liddiment saw the combined effect of these changes as offering viewers a broader, more diverse and exciting dramatic experience than before:

[W]e've transformed the way we make programmes. Until a couple of years ago, each episode would probably have more than four or five different settings - either the shop or café and 
two or three interiors of houses, plus, at the most, two scenes shot outside on the street set or at a separate location. And each episode would have no more than 14 scenes. A typical episode now has eight or nine different interiors and four outside locations, and anything up to 22 or 23 scenes. We go more on location. We see more of Weatherfield than we used to. We see more of the street. At one time, that wouldn't have happened because it was a luxury the schedule didn't allow, but we make TV now with lighter equipment that requires less lighting, so you've got more time. xi

Watson's predecessor as producer, Bill Podmore, was more sceptical about the changes, expressing concern about overkill dissipating viewers' attachment to the series, and the increased volume of characters and storylines:

New houses are to be built along the street and inevitably the cast must grow. It worries me just how many characters the viewers can absorb and care about. The more characters you have, the more each individual is diluted. xii

To incorporate the third episode, Coronation Street's weekly production schedule had to be adjusted. A typical 1980s production week allocated all location filming (mostly of Street exteriors) to Monday mornings, followed by two and a half days in the rehearsal 
room, before studio recording between Thursday afternoon and Friday evening, in time for editing and dubbing over the weekend.xiii

By 1990, the working week was extended by a day, with outside location recording on Sunday, Street exteriors on Monday, rehearsals on Tuesday and Wednesday morning, before two full days of studio recording on Thursday and Friday. xiv Although some rehearsal time survived in 1990, by the end of the decade (and the addition of a fourth episode in 1996) formal rehearsals were abandoned.xv

This chapter considers the implications of these changes through textual analysis. How was the tenor and tone of the series affected by the new modes and forms of production? And how was the way that Coronation Street functioned (and was understood by viewers) as a drama altered by greater scope of location, more characters, new houses and twice as much airtime?

Comparative analysis of the topography of Coronation Street in January 1979 and January 1991

The ten episodes of Coronation Street broadcast in 1979 operate around a limited number of interior studio locations, all regular sets at Granada Studios. Events are shown in five houses (numbers 1,5, 9, 11 and 13) and four businesses (The Rovers Return, Dawson's Café, Corner Shop and Kabin newsagent) located either on or adjacent to Coronation Street. Only one other interior studio location is shown, Baldwin's Casuals, a clothing factory run by and employing many of 
the programme's regular characters, formed onscreen of two rooms, a sewing room and adjoining Manager's Office. Across these nine buildings, events are shown in 14 rooms.

Apart from Coronation Street itself, Greater Weatherfield exterior filming is limited, confined to a nightclub doorway on New Year's Day and the exterior of a block of Council flats. One episode (\#1878) features no filmed inserts whatsoever.

Only one other interior location is used in that month's run, an unnamed supermarket acting as site for a comic storyline in which Suzie Birchall falsely claims to have won an upmarket job as a perfume demonstrator while actually working as a sausage chef. With this plot only running for two episodes (\#1879 and \#1880) it could only have been practicable and affordable to film on location, rather than to construct a supermarket set in Granada's studios. As realised on screen, the filmed nature of these sequences separates them from the rest of the programme, giving them a different feel and effect. While the convention of $16 \mathrm{~mm}$ filmed inserts is easy to adjust to when watching exterior scenes (our perception of lighting and acoustics is very different when we step outdoors in real life), the effect of filmed footage is different when used for interiors, turning the supermarket into a location, visually comprehended as being an other place, as opposed to another place, with different conditions and expectations to studio interiors. 
This sense of apartness works in the supermarket plot's favour within the wider dramatic narrative of that month's Coronation Street. The viewer's emotional interest in Suzie's downfall is reliant upon the possibility of the character being found out and humiliatingly exposed (as inevitably happens, gossip Hilda Ogden seeing Suzie). When Suzie's job is presented in a different, filmic, visual register to the rest of Coronation Street then the prospect of the familiar Coronation Street world encroaching upon her new existence carries particular disruptive force for the viewer. The sense of mild disjuncture picked up by the viewer in rare sequences like this supermarket storyline worked largely because of the exceptionalism of such locations in the programme at the time, when Greater Weatherfield was rarely visited.

By the 13 episodes of January 1991 the terrain covered by Coronation Street has greatly expanded, with scenes in eight houses $(1,4,6,7,9$, 10a, 13 and 15a) and five businesses (The Rovers Return, Corner Shop, Kabin, Casey's Garage and Jim's Cafe) on or adjacent to the Street. Across these 12 buildings, events are shown in 20 rooms.

The most striking difference between 1979 and 1991 is that flexible location recording now means that much more of the drama occurs away from the street. In addition to many unidentified road and street exteriors, scenes routinely occur in 'other' pubs or homes. The speed with which location recording could be set up meant that relatively brief scenes requiring outside locations could be shown from multiple perspectives; for example, an argument in a branch of the 
'Weatherfield \& General Building Society' (\#3181) happening in two rooms of the building. Scenes even happen in places beyond Weatherfield (a pub on the A69, a Manchester department store) without being presented as exceptional occurrences.

A major change in the series' topography is the types of workplaces regularly featured. Many scenes occur in Bettabuys Supermarket, a business that employs (at both junior managerial and more menial levels) several of the Street's residents, as well as introducing a raft of new semi-regular characters. xvi Unlike the studio-based Baldwin's Casuals, Bettabuys was a real supermarket location, creating a different sense of workplace. Where events in Baldwin's Casuals were confined to the factory floor and manager's office, Bettabuys action over the month extends over seven locations; shop floor, manager's office, canteen, corridors, loading bay, storeroom and ladies' lavatories.

This range of spaces increases dramatic possibilities for workplace scenes, creating many more opportunities for characters to be seen by, react to, and gossip about, each other. Each room carries different specific social rituals and expectations that can be observed or disrupted by the people within it; it is taboo for workers on the shop floor to make scenes in front of customers, the canteen between shifts is an suitable place and time to discuss personal matters, the lavatory is the safest place of retreat when upset but an enemy or boss may overhear you there, and so forth. New opportunities created by OB 
recording for regular settings like Bettabuys maintained the sense of familiarity that viewers had found in studio workplaces, but relocated into the type of verisimiliar outside world setting previously only seen infrequently and fleetingly in the Street, as in the 1979 supermarket story.

\section{Episode 2956 (27 July 1989)}

This episode, by Paul Abbott, is an early demonstration of how OB location recording could tell familiar stories in unfamiliar ways. The philandering Mike Baldwin plot is unoriginal ("Mike admits to Alma that he took Dawn out. Alma tells him she loves him but he tells her he's not after love"), but located in a beer garden in a previously unseen canal-side district of Greater Weatherfield. The scene is shown through a simple camera set up, an establishing shot of the leafy sunny pub followed by alternating close-ups of Mike and Alma.

The unfamiliarity and attractiveness of the location raises the dramatic stakes of the scene. Because Mike has taken Alma to a better class of venue the insensitivity of his actions is made to seem more jarring, accentuating Alma's display of disappointment and hurt. The dramatic function that such an unexceptional, rather brief, 80second dialogue scene could take within the context of the episode's narrative was a new development for Coronation Street in 1989. Such scenes were not attempted under earlier recording conditions, when the difficulty and expense of outside location filming meant that those 
few settings that were used had to be dramatically imperative to the story told, as in the supermarket plot. Previously such scenes would of necessity have occurred in permanent settings like the Rovers or the cafe.

The narrative usefulness of quick economic OB recording is also demonstrated in a 40-second sequence where Alma's friend Audrey consoles her on a walk in the park. The open location, away from home and workplace interiors, allows characters a space for reflection and evokes a specific sensation of summertime for the viewer, a sense of the passing seasons something previously largely missing in Coronation Street.

\section{Multi-camera, single camera and editing.}

Although there was no one single moment of change in studio recording practice equivalent to the switch to OB locations, incremental changes in camera and editing technology continually altered the form and style of 1990s Coronation Street. Although studio interiors continued to be recorded on three cameras, the introduction of Avid editing technology enabled much easier, and more frequent, postproduction of scenes, ${ }^{\text {xvii }}$ while changes in camera technology introduced more sophisticated focusing and higher definition images than before. Here I compare an instance when tried-and-trusted multi camera technique inhibited the full dramatic realization of a scene with an early use of higher-definition single camera recording. 


\section{Episode 3920 (11 October 1995)}

The pattern of shooting studio interiors in the 1990s required recording up to thirty scenes with three cameras over two days, the director having marked around 400 separate shots on the camera script, encouraging familiar recognized patterns of camera movement and mixing to be followed. xviii Ostensibly, this episode's final scene should have been ideally suited for recording under such wellestablished conditions. The scene, an important part of the plot leading to the departure of one of the programme's longest running and best-loved characters, Bet Gilroy, shows a climatic argument and irrevocable falling-out between old friends, material seemingly meat and drink to Coronation Street. Bet, presented with the opportunity but lacking sufficient funds to buy the property and licence of the Rovers Return, believes that her old friend Rita will offer finances to go into managerial partnership together.

The confrontation in the Kabin newsagent, shot on two cameras, revolves around a simple rise-and-fall reversal of Bet's expectations. Rita and Mavis Wilton work behind the counter when Bet arrives brandishing a bottle of champagne, having secured a reduced price for the pub from the brewery. When Rita tells Bet that she won't go through with the venture a furious row ensues, with Bet leaving the shop. 
This story is presented in simple visual terms with action confined to alternating close-ups of Bet and Rita, bookended by before-and-after mid-shots of Bet entering the Kabin doorway in triumph and departing in high dudgeon. The clear presentation accentuates the combative rhythms of the argument, allowing the viewer to observe the delivery of, and reaction to, each truth-telling insult ("It was Len's cash what got you started! But for him, you'd be a clapped-out chorus girl!" "Better than a clapped-out barmaid") and experience the considerable pleasure of observing, in close-up detail, the teethbearing, gimlet-eyed fury of two elaborately-coiffured and made-up women in advanced middle-age.

Unfortunately, this two-camera switching also prevents the scene achieving its full dramatic potential. The third woman present during the confrontation, Mavis, is neglected by the camera, leaving her contributions to the scene marginal and incoherent, a blurry and muffled presence in the corner of the frame, accidentally hinted at in a momentary sideways glance from Julie Goodyear (Bet). Mavis' actions in the scene are hard to discern when first watched, and only after several viewings (an option unavailable to the original viewer) can one establish precisely what happens to her: she becomes, mumbles a suggestion that Bet and Rita might have their discussion somewhere else and, despite being at work, walks out of the shop in embarrassment. As presented onscreen, this strand of the story is 
overlooked, with Mavis seen only as a hand fluttering behind Rita and the back of a head momentarily passing in front of Bet.

It is instructive to imagine how this scene would be viewed if performed in a theatre, where an audience would be as aware of the Mavis' presence as Bet and Rita's, and potentially in sympathy with her: not knowing how to respond when other people are arguing can be as dramatically interesting as an argument itself. Although the dramatic faults of this scene would not necessarily be alleviated through single-camera technology and ability to edit in separately recorded shots (and might risk diluting the rhythm of the argument), their use would necessitate more systematic consideration of the problem of Mavis' invisibility before recording.

\section{Episode 3416 (29 July 1992)}

In contrast, this episode provides an extremely early example of single camera recording and extensive postproduction of studio scenes in Coronation Street. This stylistic experimentation appears to have been born of necessity, with one comic storyline impossible to record under conventional conditions. Rovers landlord Alec Gilroy buys a rare Mexican mouse-eating spider, which escapes during a kitchen inspection from an environmental health officer. The spider's performance is shot in separate cutaways.

The directorial style demanded by the kitchen scenes, presenting details and features in close up detail and precise definition, carries 
over onto other interiors throughout the episode, ${ }^{\text {xix }}$ in which the misfortunes of Ivy Brennan form a tragic counterbalance to the comic spider story. Having had his foot amputated after crashing his taxi in a suicide attempt (after Julie broke off their affair), Don is discharged from hospital, but refuses to return to Ivy. The vigil of waiting is presented through concentration upon objects in the foreground (vase of fresh flowers, silent telephone and bottle of sherry) with Ivy's movements and conversations with daughter-in-law Gail in blurred focus in the background of the frame. This unconventional arrangement demands the viewer's full attention and, unlike the misdirected "snooping on Don Brennan from the back garden" instance, serves an intentional storytelling purpose. Concentration upon the objects handled, rather than the woman handling them, encourages understanding of Ivy's agitation and disconnected state of mind, and is as close as Coronation Street comes to a point of view shot in this period.

The jarring ontological unfamiliarity of this new technique proves counterproductive. If seen in a one-off ITV drama in 1992, such visual devices would offer narrative clarity for the viewer, but when used in Coronation Street, a programme with a familiar visual style accrued through 32 years of studio practice, the direction draws as much attention to itself as it does to the story, the unfamiliar style confusing Ivy's plight as much illuminating it. The directorially prescriptive style puts little trust in viewers' imaginative ability to appreciate nuances of 
character revealed through the detail of actors' performances, a traditional Coronation Street strength. When seen from a present-day perspective, the episode (which experiments with sound as well as vision, continuing the soundtrack of one scene onto the visuals of the next) appears out-of-time, placing the world of 1992 into the television style of about ten years later.

\section{Plot inflation.}

1990s Coronation Street operated in a more crowded and competitive broadcasting environment than in previous decades, with terrestrial television ratings, squeezed by the rise of the video recorder in the 1980s, further challenged by the introduction of U.K. satellite and cable broadcasting in 1989. With soap operas attracting a regular audience to their host channels, all four major British serials increased output in the 1980s and 1990s, Emmerdale (Emmerdale Farm until 1989, ITV, Yorkshire Television 1972-) being the last to introduce a third episode in 1997. When combined with the perpetual pressure to keep series in the public eye, this increased volume of production has led to the 1990s growth period of soap operas to be described as a time of greatly increased sensationalism in soap operas. ${ }^{x x}$ Jimmy McGovern identified this trend:

Inflation has set in. The Street used to be immune to it but even there writers are losing faith in actors, and the actors are losing faith in the characters. So people have to place great faith in the 
stories. But that's when inflation sets in because one story has to top another. $x x i$

To suggest that Coronation Street had somehow avoided sensational storylines before the late 1980s would be a misrepresentation. The recurrent need, faced by all continuous series, to write actors out necessitates the regular recurrence of marital breakdown and sudden death. Although the Street didn't suffer its first murder until the shooting of Ernest Bishop in 1978, its unfortunate residents had already experienced many shocking demises; crushing by van, suicide, electrocution by faulty hairdryer. Nor had it avoided spectacular disasters, enduring train and lorry crashes in 1967 and 1979. The particular change to Coronation Street in the 1990s lay in the form that such calamities took, as well as the frequency with which they occurred. Previous shocking events such as Minnie Caldwell being held at gunpoint (1970), or Deidre Langton being sexually assaulted (1977), happened in the familiar location of Coronation Street itself, the intrinsic sense of community derived by long-term viewers from the setting making such exceptional storylines disruptive and memorable, encouraging empathetic feeling for regular charactersbecome-victims.

An early example of the changing presentation of potentially sensational violent events in Coronation Street is the collapse of Mike Baldwin's second marriage, a week after the wedding (\#3251, 12 July 1991). When wealthy widow Jackie discovers the full extent that Mike 
has attempted to defraud her through matrimony, she threatens him with a loaded shotgun when he returns home. Although this violent scene would be always freighted with problems of basic implausibility wherever it was set, the unfamiliar Greater Weatherfield location (Elmsgate Gardens) handicaps its ontological integration into the imaginative world of Coronation Street. The location (a real house, not a studio set) has only been previously seen in a handful of episodes and carries few emotional associations for the audience, so such a violent event carries less in disruptive force than it could otherwise: people might do such things all the time in Elmsgate Gardens, for all that the regular viewer knows. When such sensational events occur away from the understood community of Coronation Street, audiences view them as separate from other incidents in the programme, and they come to carry less emotive power.

\section{Episode 4179 (18 April 1997)}

By 1997, spectacular and shocking events were almost commonplace in the four-times weekly Coronation Street, realised on a much grander scale than the gun-toting Jackie Baldwin sequence of six years earlier. Advances in PSC (Portable Single Camera) technology and a more flexible recording schedule allowing greater leeway for recording out of sequence made it more possible to mount highly ambitious sequences. 
The events of this hour-long special present an outstanding example of this process in practice. ${ }^{x x i i}$ The episode portrays the actions of a crazed Don, who has contrived a vendetta against Mike, having recently set fire to Baldwin's factory. He picks Alma (now Mike's third wife) up in his (unlicensed) taxi one night, drives past her stop, locks her in, and refuses to let her leave. At a deserted quayside, Alma tries to call for help on the taxi radio, which Don rips out and destroys. After Don hits her Alma breaks free, but Don chases her in the car and forces her back into the cab. He drives the taxi straight into the River Irwell at the Quays, with them both inside it.

This vivid storyline comprised the most elaborate and technically demanding sequence yet attempted in Coronation Street, requiring five separate 12-hour night shoots involving trained stunt people and underwater filming, a process compared by Coronation Street's producer to making a James Bond film.xxiii The use of PSC editing does create a cinematic feel, facilitating extreme close-ups of Brennan's eyes reflected in the rear-view mirror, quick edits of spectacular dangerous driving, shots rotating around the ragged couple on the deserted quayside, POV shots of the driver stalking his quarry, and so forth.

The same token that makes this storyline spectacular also makes its integration into the world of Coronation Street problematic. The kidnap plot forms 15 separate sections, some very brief, within the episode. Each time that the action returns back to the Street from the 
frightening wastelands of Greater Weatherfield, the viewer is forced to readjust to a different, ontologically familiar, world. Although this juxtaposition of Rovers Return and terrifying Quayside ordeal is freighted with dramatic ironies, it dominates the overall narrative of the episode, giving more subdued plots, such as recently widowed Mavis' grief, less room to establish themselves than might otherwise be the case. While it was impressive that 1997 Coronation Street could capably achieve a convincing thriller kidnap plot, similar plots could be found in many other drama programmes of the time, such stories preventing Coronation Street from creating distinctive drama unique to itself.

The place of this story within the wider narrative of 1997 Coronation Street also demonstrates the questionable sustainability of a series in thrall to plot inflation. Kidnap, quickly following arson, wasn't the climax of Don's irrational behaviour, which eventually arrived six months later when, attempting to run Mike over after failing to club him to death, Don died in an explosive car crash (\#4278). Spectacularly violent events risk becoming less of a talking point once they become regular occurrences.

\section{Conclusion}

Through textual analysis, this article has demonstrated that two concurrent changes undergone by Coronation Street at the end of the 1980s (greater, more extensive, location recording and the 
introduction of a third episode) radically affected the programme's form, and how viewers understood it. The greater amount of airtime to fill encouraged the creation of more sensational and protracted storylines. The 1990s world of Coronation Street expanded beyond the Street's immediate confines into Greater Weatherfield, a place that bore more visual similarities to the wider world, but which undermined emotional and imaginative ties viewers had formed with the familiar Street itself.

i Geraghty, Christine. 'Exhausted and Exhausting: Television Studies and British Soap Opera'. Critical Studies in Television 5/1, Spring 2010, pp.82-96.

ii Ibid, p. 91.

iii Little, Daran. 40 Years of Coronation Street. London: Andre Deutsch, 2000, p.188.

iv Hanson, David and Kingston, Jo. Coronation St.: Access All Areas. London: Andre Deutsch, 1999, p.58.

v Kay, Graeme. Life in the Street: Coronation Street Past and Present. London: Boxtree, 1991, pp.24-5.

vi Ibid.

vii Ibid, p.31.

viii Hanson and Kingston, 1999, p.51.

ix Podmore, Bill and Reece, Peter. Coronation Street: The Inside Story. London: Macdonald, 1990, p.171.

x Hanson and Kingston, 1999, p.98. 
xi Kay, 1991, pp.26-28.

xii Podmore and Reece, 1990, p.178.

xiii Ibid, p.169-73.

xiv Kay, 1991, p.62-3.

xv Hanson and Kingston, 1999, pp.76-7.

xvi Most notoriously, manager Reg Holdsworth, a character who dominates many viewers' early '90s memories of Coronation Street.

xvii Hanson and Kingston, 1999, pp.100-1.

xviii Kay, 1991, p.63.

xix The episode's director, Brian Mills, had developed a reputation for visual invention in Coronation Street's, e.g. his decision to shoot climactic scenes of the 1983 Mike-Deirdre-Ken love triangle from overhead angles.

(http://www.independent.co.uk/news/obituaries/brian-mills409180.html )

xx Kibble-White, Jack. 'Everyday Folk and Inflation', http:/ /www.offthetelly.co.uk/?page_id=276, 2000. By 2012, the process of plot inflation in Coronation Street had accelerated to such extent that Roy Hattersley could describe the series as suffering from "homicide exhaustion" (http://www.dailymail.co.uk/tvshowbiz/article-2114172/CoronationStreet-After-10-violent-deaths-time-bulldoze-soap.html)

xxi In Jeffries, Stuart. Mrs Slocombe's Pussy: Growing Up in Front of the Telly. London: Flamingo, 2000, pp. 170-1. McGovern wrote one episode of Coronation Street (\#3115) in August 1990.

xxii Double-length episodes were a 1990s innovation, first attempted in \#3945 (8 December 1995).

xxiii Hanson and Kingston, 1999, pp.94-5. 